\title{
Co-Creation with Amateur Designers via Open Innovation
}

\author{
Joosung Lee ${ }^{1 *}$, Ying Wang² \\ ${ }^{1}$ Division of Convergence and Entrepreneurship, Soonchunhyang University, Asan, South Korea \\ ${ }^{2}$ Department of Design, Politecnico de Milano, Milano, Italy \\ Email: *jsl@sch.ac.kr
}

How to cite this paper: Lee, J., \& Wang, Y. (2020). Co-Creation with Amateur Designers via Open Innovation. American Journal of Industrial and Business Management, 10, 544-563.

https://doi.org/10.4236/ajibm.2020.103037

Received: January 30, 2020

Accepted: March 9, 2020

Published: March 12, 2020

Copyright (c) 2020 by author(s) and Scientific Research Publishing Inc. This work is licensed under the Creative Commons Attribution International License (CC BY 4.0).

http://creativecommons.org/licenses/by/4.0/

\section{(c) (i) Open Access}

\begin{abstract}
This research presents a literature review and a series of short cases on amateurs' participation in collaborative innovation process. Amateurs are generally considered as non-professionals to a particular pursuit, study, or science. In new product/service development, amateurs are the ones that do not have the occupation as professional designers, but still have the ability or willingness to participate in the innovation process. The concept of "amateur" discussed here is different from "user". The results of the literature analysis and case studies proved that amateurs' participation already contributed to companies' idea generation, and even had commercial success in some industries. Some suggestions are given for assisting amateurs and designers to adapt to the new design process changes, and rules are offered for the companies to localize their collaboration mode with a long-term strategy.
\end{abstract}

\section{Keywords}

Amateur Designer, Co-Creation, Open Innovation

\section{Introduction}

An amateur is generally considered as a person attached to a particular pursuit, study, or science in a non-professional or unpaid manner. In this article, amateurs are the ones that do not have the occupation as professional designers, but still have the ability or willingness to participate in the innovation process. The concept of "amateur" discussed here is different from "user". The "user" is someone who directly gets in touch with a specific product or service, while the "amateur" here is related to the design innovation industry for any single product.

With different degrees of design knowledge and capability, the amateurs could 
be classified into three types that be expected with different participation level and under different guidance. Firstly, design-related amateurs, who worked in design-related industry, but had not worked as a professional designer. For example, design students, folk artists, and craftsmen have certain skills which could directly apply to the design process.

Secondly, arts/craft-interested amateurs who do not work on design-related industry, but have interest in this area. For instance, design fans, handcrafts lovers, and new trends captors' groups are normally eager to express themselves though individualized products and glad to show off their talent and skills by participating in design progress.

And the last group is other experts, the ones who stand far away from design and related industry, but have knowledge in other innovation fields. These amateurs are not only the experts in economics, social science or technology, but also could be subject experts in tiny industrial or daily affairs, for example, housewives as the experts in home cleaning.

The basic research question in this article is: How do amateurs participate in collaborated innovation and what role can be expected for the future? This report aims to sum up the existing model of amateurs' participating in the collaborative innovation, compare and analyze them, and finally explore the new co-creation possibilities. In order to define the answers, this research will review the range of applications of amateurs' participating in collaborative innovation, based on the current literature and the selected cases. The literature review and the case studies offer deeper discussion and meaningful prospects for innovative product/service development.

\section{Literature Review}

"Open collaborative innovation" refers to development projects in which multiple users collaborate and openly share what they develop (Von Hippel, 2005; Casati, 2012). It is a concept developed from "open innovation" (Levine \& Prietula, 2013; Hitotsuishi, 2012), used to describe a category of "open innovation" in a pattern of collaboration, innovation and production. "Open innovation is a paradigm that assumes that firms can and should use external ideas as well as internal ideas, and internal and external paths to market, as the firms look to advance their technology". Opposite from "closed innovation" in Figure 1, "Open innovation" is defined by Chesbrough (2003) as the "use of purposive inflows and outflows of knowledge to accelerate internal innovation, and expand the markets for external use of innovation, respectively." The diagrams below well explain the difference between open innovation and traditional closed innovation, and the possibility of integrating out-sourcing into the new product/service and market development process.

According to Claudio Dell' Era and Alessandro Sala's framework in Figure 2, collaborative innovation could be divided into four types: the "Innovation Mall" which is open participating and with hierarchical governance, "Community Innovation" which is open and flat, "Elite Circle" to explain the ones who are 

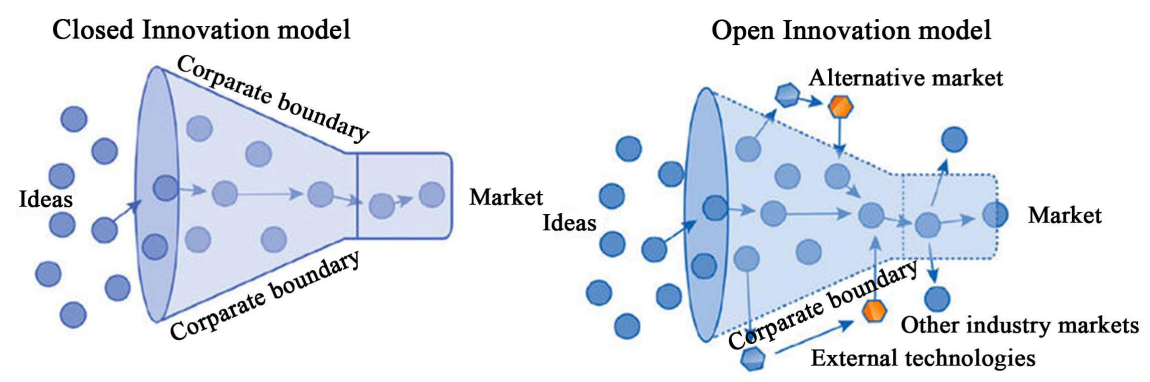

Figure 1. The closed (left) vs. open (right) innovation model. Source: Chemeurope.com.

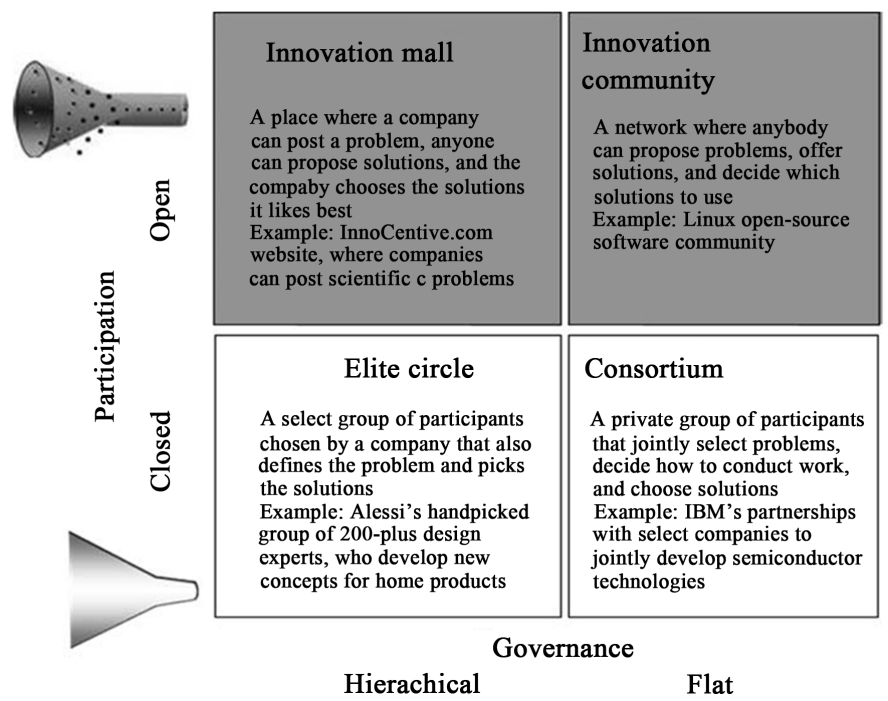

Figure 2. Collaborative innovation framework', from 2013 Business Innovation Lecture, Claudio Dell'Era and Alessandro Sala, and Cairn.

closed and hierarchical, and "Consortia" means closed and flat. Among them, the first two: "Innovation Mall" and "Community Innovation" are exactly the subject of this study.

In this research, when "open collaborative innovation" is discussed, two levels of collaboration need to be analyzed: firstly, the ordinary amateurs cooperating with designers and other experts in the company; and secondary, the amateurs collaborating with each other to self-innovate.

\subsection{Amateurs' Willingness and Capabilities}

Amateurs' experience contributes to design process. Empirical studies show that many of them- from 10 percent to nearly 40 percent-engage in developing or modifying products (Von Hippel, 2005). In the past, amateurs already got many achievements on new product development, for example, Gatorade in the healthcare field, protein-based shampoo and feminine hygiene in the personal care industry, and the mountain bike and mountain climbing-piton in the sports equipment industry as shown in Table 1. If so many excellent products already co-developed by amateurs, companies and society have sufficient reasons to expect more in the future. 
Table 1. Examples of important products created by lead-users. Source: von Hippel, 2003.

\begin{tabular}{cc}
\hline Category & Example \\
\hline Health Products & Gatorade \\
Personal Care & $\begin{array}{c}\text { Protein-base Shampoo } \\
\text { Feminine Hygiene }\end{array}$ \\
Sports Equipment & Mountain Bike \\
Apparel & Mountain Climbing Piton \\
Food & Sports Bra \\
Office & Chocolate Milk \\
& Graham Cracker Crust \\
Computer Application Software & White-out Liquid \\
& Electronic Mail \\
\end{tabular}

A creative amateur based on individual creativity is active in all areas, and its importance is stronger than ever before (Telalbasic, 2012). Different from the traditional opinion of "people with the problems" before, more and more researchers start to set the point of view that recognizes the "ordinary people" as "people with capabilities". As Ezio Manizni mentioned in the thesis of "People-as-asset", nowadays developing design solutions must be based on people's expertise and capability. They are to be actively involved in the solution conception (co-design) and delivery (co-production) because people are equipped with knowledge, time and energy for useful contribution (Manizni, 2013a).

There are several reasons that lead to these changes. The most obvious reason is that people are not satisfied with the products they own. Because most manufactures tend to produce for the dominant needs in the market, so a lot of other potential interests are easily ignored. There is also another reason: from the creative activities, users truly enjoy the happiness and the sense of achievement. For a lot of amateurs, creative design such as arts, are a kind of "game" in which they would like to participate even if not payed. The last but not the least, people's psychological needs are changing in these several years.

\subsection{Present Collaboration Mode and Condition}

Some existing modes were created to involve amateurs in design activities. From Lee Woo-hun's model (2013) in Figure 3, there are four main ways that people can participate in the design process: 1) DIY where non-professional people create things by themselves, 2) appropriating as non-professionals re-purpose the existing products, 3) hacking where professionals use their specific knowledge to adapt the products to their own use condition, and 4) design as the professional designer creates products. This model used a clear and concise diagram explaining the relationship between non-professional and half-professional amateur designers' activities and work. Based on this diagram, exploring other amateur collaboration modes and their specific roles and activities with these different modes, is the main objective of this research. 


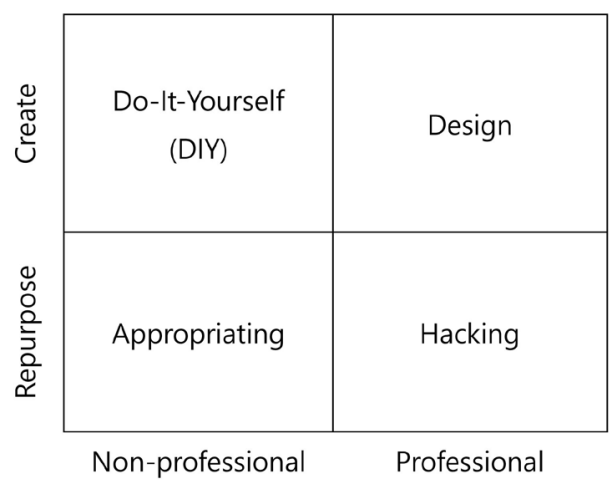

Figure 3. User participation model, from Lee Woo-hun, Design Project Lecture, KAIST, 2013.

Amateurs' participation not only changed their own roles, but also changed designers' role in the design process. Traditionally, designers were asked to recognize technological innovations and translate them in socially acceptable products/services. When amateurs are involved, professional designers are not isolated anymore, they need to learn to work with many non-professional ones. In this new context, design experts have to do more in bringing specific design competences in co-design processes. Their new task is considered to focus on people's capabilities and to conceive and develop the solutions (Manizni, 2013b).

Amateurs' participation also influences the business model (Osterwalder \& Yves Pigneur, 2010) of the companies. At the age of economic uncertainty, large manufacturing companies became more sensible to user needs and try their best to get insight how to appeal to users. They developed new strategies that changed the in-house developing to collaborative innovation and out-sourcing. Thus searching the methods and cases to manage amateurs' participation remains an urgent task today.

However, even amateurs have strong willingness to get involved in co-creation, dispersedness of people make open collaboration not as efficient as designer-centered innovation. Even there are some platforms to record tiny innovations and let people directly or indirectly cooperate, there is still a long way to go forward. And also, open collaborative innovation is regarded "waste of resource" by putting too much effort in recording, organizing and balancing different people's ideas, time and man-power. Because of this, the research puts more emphasis on exploring a way to organize the resources, and to help amateurs overcome their limits for higher performance on collaborative innovation.

\subsection{Technology Review}

Today's technologies are expected to improve collaboration innovation with amateurs. Mobile Internet devices by connecting people in the internet whenever and wherever, people's skills and knowledge are no longer as secrete anymore. When each person clicks the mouse and finds the specific steps to make a creative crafting-product and tries to repeat it at home, the innovation will spread 
globally much quickly. Timely skill sharing, rapid information responding and problem solving could change the way of learning and working.

Big data is the term for a collection of data sets so large and complex that becomes difficult to process using on-hand database management tools or traditional data processing applications (TIPCO, 2014). By using the big-data to record users' habits to understand their behaviors and potential needs, innovative products can be designed with a big influence on daily life.

Virtual reality is a computer-simulated environment that can simulate physical presence in places in the real world or imagined worlds. Design innovation as an art of imagination, will be impacted by virtual reality with its own transfer steps of immersion-interaction- imagination. Virtual reality gives people a chance to choose, change, and fulfill their creative dream in the 3D experience.

Rapid Manufacturing or 3D printing is a well-known quick prototyping and production method, which makes creating customized products as easy as baking a piece of bread. As cost-efficient functional 3D printers come into home, people get a new way to achieve their daily needs. More personal than mass-produced products, and more accurate and high quality than handmade products, these 3D-printed goods have their strong superiority. For example, 3D printers, laser cutters and advanced design software could be used to create a Maker-space in the community. It allows the self-make and self-remake as a new way to satisfy a need without the traditional hardware purchase.

Through the deeper understanding of the concept of "amateurs" participation in design, representative cases about amateurs' collaborative innovation are analyzed below.

\section{Cases}

\subsection{Every Use}

Every Use is an Android application made by Korea Advanced Institute of Science and Technology (KAIST) in 2013. With the application, people can share their own creative uses of everyday objects. It allows amateurs to explore the cases uploaded by other people to see the variety in the usage of the same objects or in the objects in attempts to reach the same purposes, because discovering others' creative instances can inspire the viewer to come up with own creations or find unnoticed cases. This process of viewing and uploading creative cases enabled other innovative uses as shown in Figure 4.

As an experimental project, Every Use is a unique case with good implications. All the creative modifications start from the step of appropriating. Different from the old thinking that products have their fixed "right" way of usage and all the mistakes needed to be blamed, nowadays, a number of developers and designers understand that "mistakes" should be permitted and even encouraged. Actually, "mistakes" even stimulate creativities and better solutions. Every Use leads the new trend of "learn from trials and even mistakes" and has possibility to evolve into more interesting participating and collaborating mode as shown in Figure 5. 


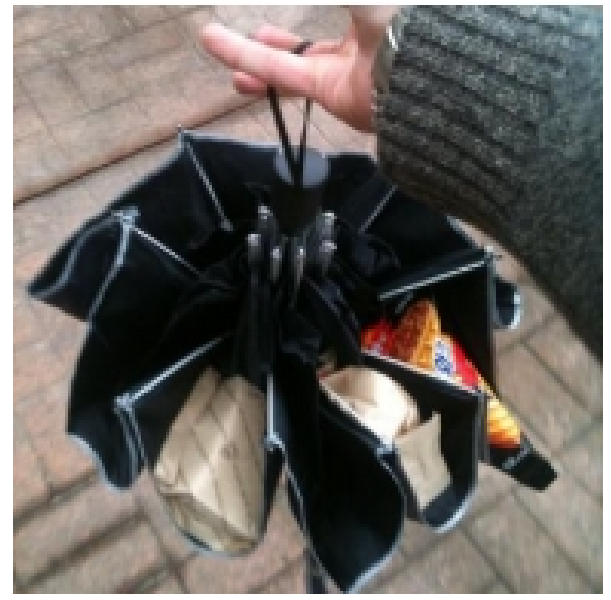

Figure 4. One case of the Every Use idea (left), from https://www.facebook.com/pages/Every Use/362007507238493.

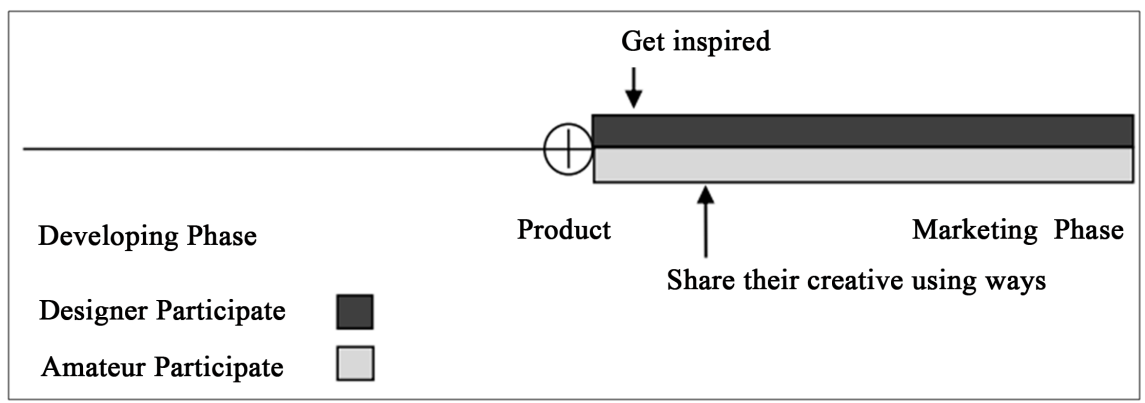

Figure 5. The collaborate phase map of Every Use.

\subsection{Pinterest}

Pinterest, which started in 2014 in the United States, is a visual discovery tool that people use to collect ideas for their different projects and interests. On the platform in Figure 6, people create and share collections (called "boards") of visual bookmarks (called "Pins") that they use to do things like planning trips and projects, organizing events or saving articles and recipes. There is also a like feature to save certain pins that may not fit with a board (Carlson, 2012).

The users can both use Pinterest as a search engine for creative ideas or interesting pictures based social network. Firstly, amateurs can share their creativities by picture or share the creative pictures they like. Secondly, they could also customize the types of the pictures they want to see according to their own interest (recognized as bookmarks). This way, the amateurs with the same tastes or hobbies could support one another and share their creativity together as shown in Figure 7.

Like the concept similar to "newspaper clipping" in the past, the users of Pinterest are housewives and moms who seem quite far away from the profession of design and innovation. However, innovation is often from the most ordinary people. By leaving the freedom to amateurs, they can actively participate into the innovation step by step. 


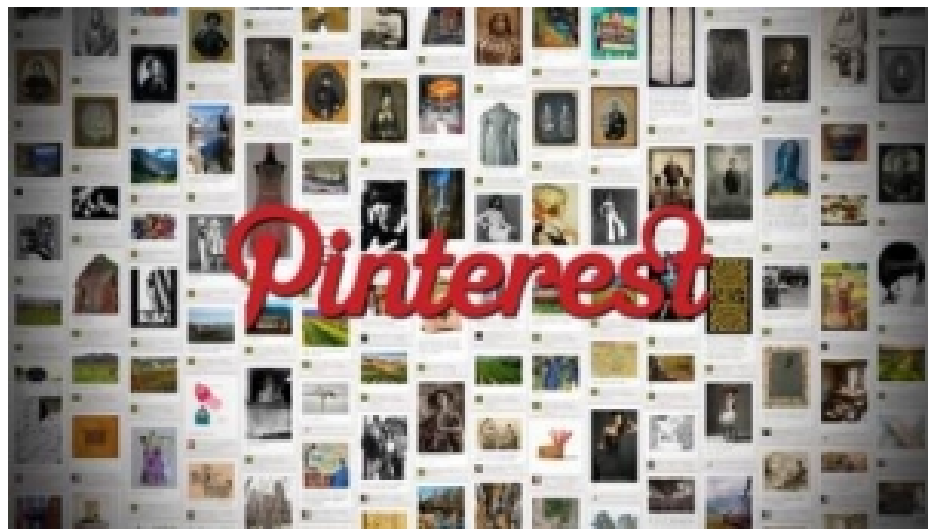

Figure 6. The interface of Pinterest website, from

http://blog.europeana.eu/2012/03/pinterest-for-glams-europeanas-experiment/.

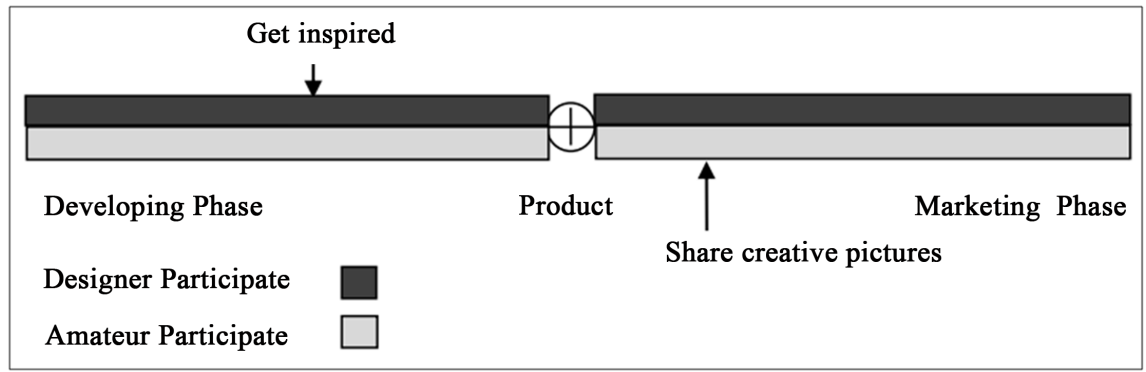

Figure 7. The collaborate phase map of Pinterest.

\subsection{0\% Tobeus}

100\% TobeUS was made by the Italian Toy Company “TobeUS" in 2012, which is an exhibit launched by an Italian architect-Matteo Ragni. It features over 100 toy cars designed by some of the world's best designers and architects. TobeUs has become synonymous with a way of design and the creation of new objects, attracting designers who want to design their own TobeUs.

During the $100 \%$ TOBEUS's off-line and online exhibitions, the amateurs not only worked as the audience to enjoy famous designers' works, but they also had the chance to design their own wooden cars as shown in Figure 8. By taking DIY card from the exhibition or download the card online, they can use their $2 \mathrm{D}$ drawing or $3 \mathrm{D}$ modeling to express their ideas. At the end, the good ones would be show out on the exhibition. However, the amateur's design process in Figure 9 was more like a game rather than creating the real products.

There is a big issue about how to let the amateurs overcome the psychological boundary and fall in love with participatory design. 100\% TobeUS set an example for the other companies. They chose the amateurs in the specific social roles-kids and parents. Normally, kids are always interested in the new area, especially painting and creating new things. Influenced by their kids, the parents worked as helpers and got in touch to the project. By designing for their own babies, they got the sense of achievement and experienced creative innovation as well. 


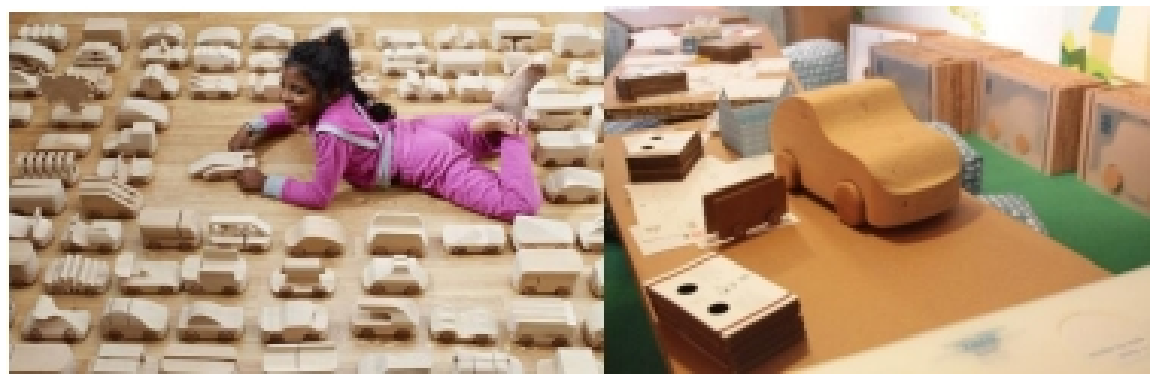

Figure 8 . The $100 \%$ TOBEUS toy cars designed by 100 famous designers (left), the design postcard for visitors (right), from http://www.100x100tobeus.it/.

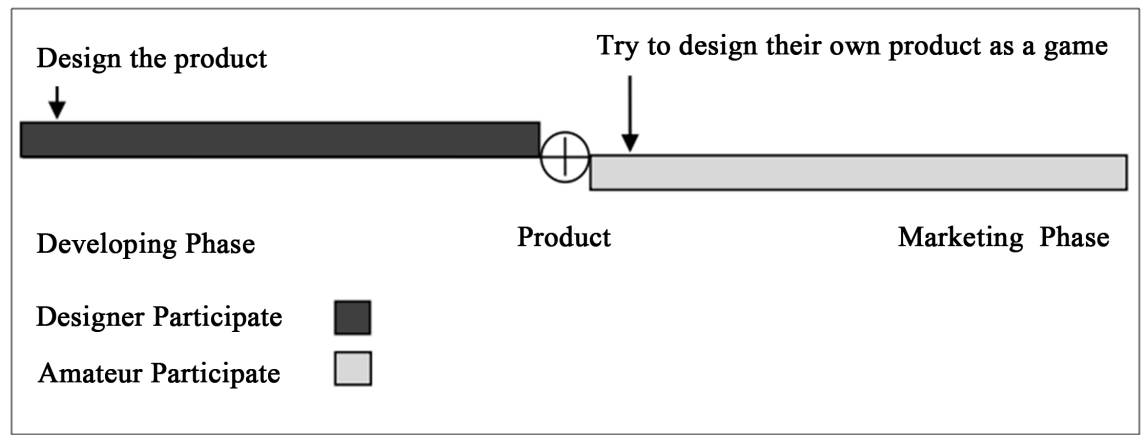

Figure 9. The collaborate phase map of 100\% TOBEUS.

\subsection{Julep}

Julep is a burgeoning cosmetics company started in 2014 from the United States. It tests and refines cosmetics with the help of their customers-people who are not paid to tell what they want. It let women work together with developers to build something they can believe in as shown in Figure 10. The mission is to ignite the spirit of engagement in women everywhere.

Amateurs can customize their cosmetics online by doing the quiz to fix their style profile and present their requirement. After that, they can buy the suggested products separately or even choose to receive a personal makeup box per month by paying a certain amount of money. At the end, they upload feedback online to improve the products and recommend them to other consumers as shown in Figure 11. Compared with other cosmetics brand, Julep push the young ladies into the centered position of products developing. They only produce the products that users have wanted and suggested, instead of persuading the users to adopt what they developed.

Julep Beauty is a pioneer company who did the trail of social-network-based products development. Because of the particularity of cosmetics industry, all the companies focused on the same group of users and exacerbate the competition. Compare with other companies, Julep get obvious advantage from co-design. By hearing amateurs' voice, they quickly improve the user experience and easily make marketing research. On the other hand, the amateurs will more willing to help to spread the brand because of the value identification. 


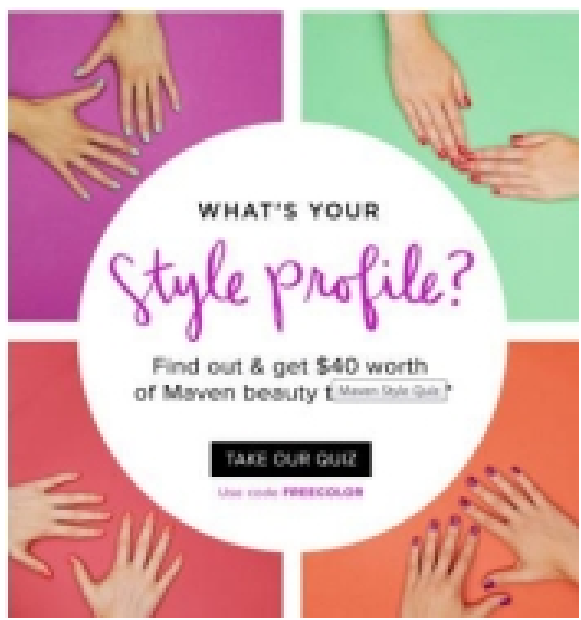

Figure 10. The advertising picture about co-design the Julep nail polish color, from http://www.julep.com/.

\begin{tabular}{llll|}
\hline Share their thinking and style & Improve \\
Developing Phase & Be used & \\
Designer Participate \\
Amateur Participate
\end{tabular}

Figure 11. The collaborate phase map of Julep.

\subsection{Casetagram}

When smart-phones sweep around the world, more and more companies put their eyes on the market of smartphone accessories. Among them, Casetagram, a brand which was founded in 2011 in USA, built a new direction to attract and involve the amateurs. Casetagram is a social design service where amateurs can design their own mobile cases using their social images. On the Casetagram online-platform, users can register with their instagram account (also Facebook and other social network), and choose their favorite photo from it to print on their cases as shown in Figure 12. For long-term users, by paying 10 dollars per month, they can get a customized case each month. In order to stimulate their sense of success, amateurs can also share the case photo on social network to express their proudness.

Offering platform for customized products had been an important trend in the design-related industries for many years. There are an increasing number of companies succeeding by this approach in Figure 13. For example, Nike ID and Mydeco are two of the most famous ones among them. For this reason, making breakthrough innovation in this direction is an urgent and difficult task for all the companies. Different from other similar platforms, Casetagram's customizing its platform linked to the photo share network. This system allows amateurs to save time additional design and to display the result as easy as a click. 


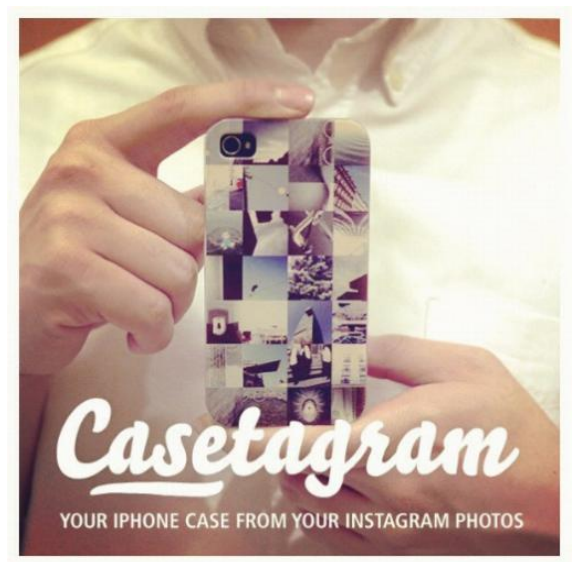

Figure 12. The Casetagram advertisement page, from http://www.tumblr.com.

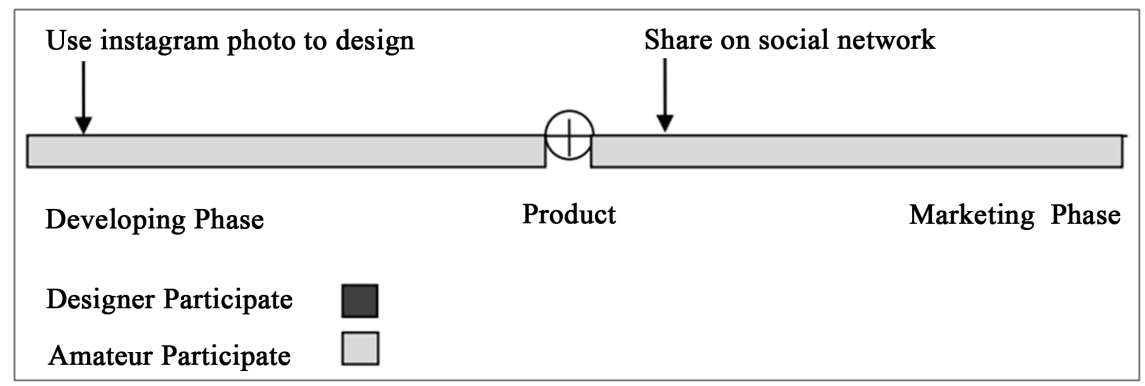

Figure 13. The collaborate phase map of Casetagram.

\subsection{Logo Tournament}

Logo Tournament, a famous crowdsourcing logo design platform based in the United States started in 2007. It is an online community where businesses can go to receive the logo they really want by hosting a logo design contest as shown in Figure 14. This provides many more ideas and variety than a traditional design firm.

There are two types of users here, one is the small companies, organizations or individuals who need a LOGO design. They fill out a logo questionnaire and set a prize amount. And another kind of uses is the professional, half-professional designers or design lovers who design the LOGO and get feedback. At last, the LOGO demanders select the winner, who will be paid. In these processes, all the design and select steps are made by amateurs themselves under the rules set by the service manager as shown in Figure 15.

The direction of amateur designer's design competition has already emerged for 10 to 20 years. This mode could mainly divide into two ways: The long term crowdsourcing hacking, as Free Lancer in Australia and Elance in USA. And the other way is short-term design competition as Designboom competition and LaunchBox in Europe. However, both of these two ways need high requirement of design capability. Normally, only design and art major students have a good chance to be the winner. However more amateurs without 2D and 3D presenting capabilities now also engage in these competitions. 


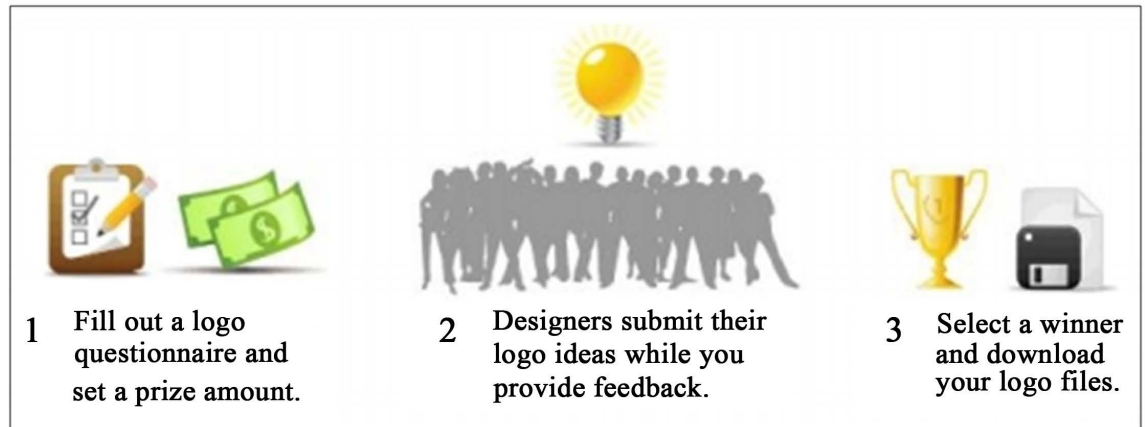

Figure 14. The basic steps of Logo Tournament, from http://logotournament.com/.

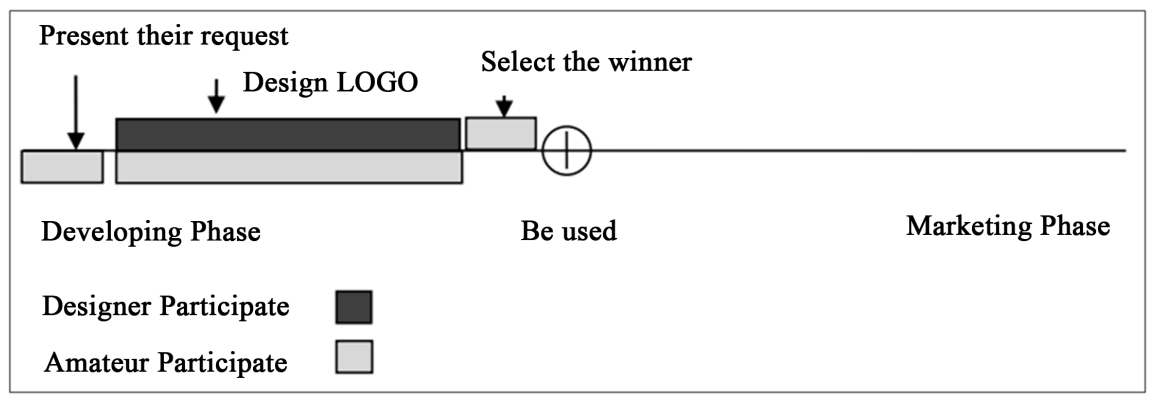

Figure 15. The collaborate phase map of Logo Tournament.

\subsection{Threadless}

Threadless is an online community of artists and an e-commerce website based in Chicago, Illinois. Threadless designs in Figure 16 are created by and chosen by an online community. Each week, about 1000 designs are submitted online and put to a public vote. After seven days the staff reviews the top-scoring designs. Based on the average score and community feedback, about 10 designs are selected each week, printed on clothing and other products, and sold worldwide through the online store and at their retail store in Chicago.

The amateurs act with four roles in this case in Figure 17. Firstly, they are the designers, who directly design and participate in the competition. Secondly, they act as artist-like community members. Though the blog, they get opportunity to contact and learn from other designers. Thirdly, they are the valuators who vote for the best works for market launch. Finally, they are also the consumers. Because of their efforts devoted in the designing process, this group of people are not only satisfied with the ordinary consumer's role, but more strongly hope to attract their friends to buy and get involved in this service.

Crowdsourcing designed T-shirt industry is considered as one of the most popular crowdsourcing business. It presents different characteristics in different countries and regions. Threadless is famous for its modern style T-shirts, while Graniph in Japan shows a concise style. On the contrary, in some developing countries without a strong art culture, this mode has not been successful. Before thinking about attracting more people to participating in design, cultivating creative culture in the local society is a more significant issue. 


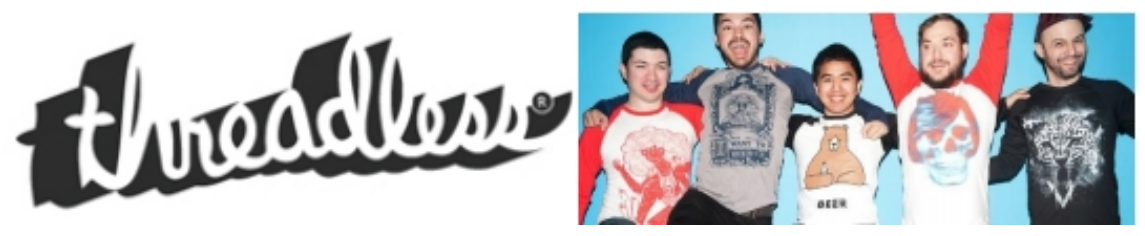

Figure 16. Logo of Threasless (left), Examples of the T-shirts (right), from https://www.threadless.com/.

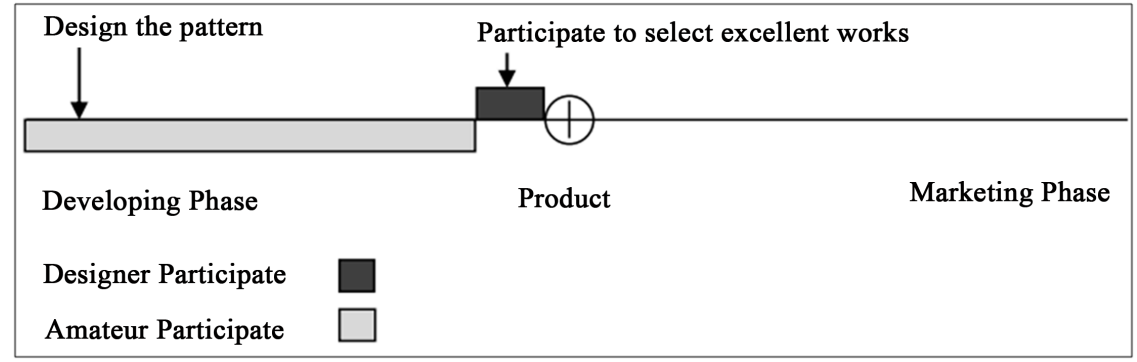

Figure 17. The collaborate phase map of Threadless.

\subsection{Quirky}

Quirky is a New York City based invention company which was founded in 2009. The company in Figure 18 makes invention accessible by bringing real people's product ideas to life. To take ideas from sketchbook to store shelves, in-house designers and engineers collaborate with Quirky's online community on nearly every aspect of development. Anyone can make their mark by submitting a problem-solving idea or weighing in on others. And when a product is sold, they share a cut of the revenue with all those who had an impact.

Amateurs can submit their ideas to start the journey of bringing them to real life. Then they could also help to decide the promising ideas and offer suggestions for them. Every Thursday, the company gathers a group of industry experts, friends and community members to debate the best ideas that have been submitted, and chose the next products that they will begin working on. After that, the amateurs can still help to decide something as simple as what color that the products should be made, or even as complicated as how to solve an engineering issue as shown in Figure 19. According to the co-design result, the company uses the manufacturing techniques to make products. And at last, these products sell on the online shop and the idea owner would get profits as well as other people's respect.

Compared to Treadless, Quirky uses the same kind of structure and business logic, but requires more complicated operation condition. It makes use of $3 \mathrm{D}$ printing to build a prototype for the promising idea. On the other hand, their distribution chain is more developed, from online shop to off-line supermarket, making the ideas permeate into people's daily life. However, this mode also faces the similar difficulties. It is hard to apply in some developing countries, partly because there are still a lot of amateurs who think that any good idea should be 


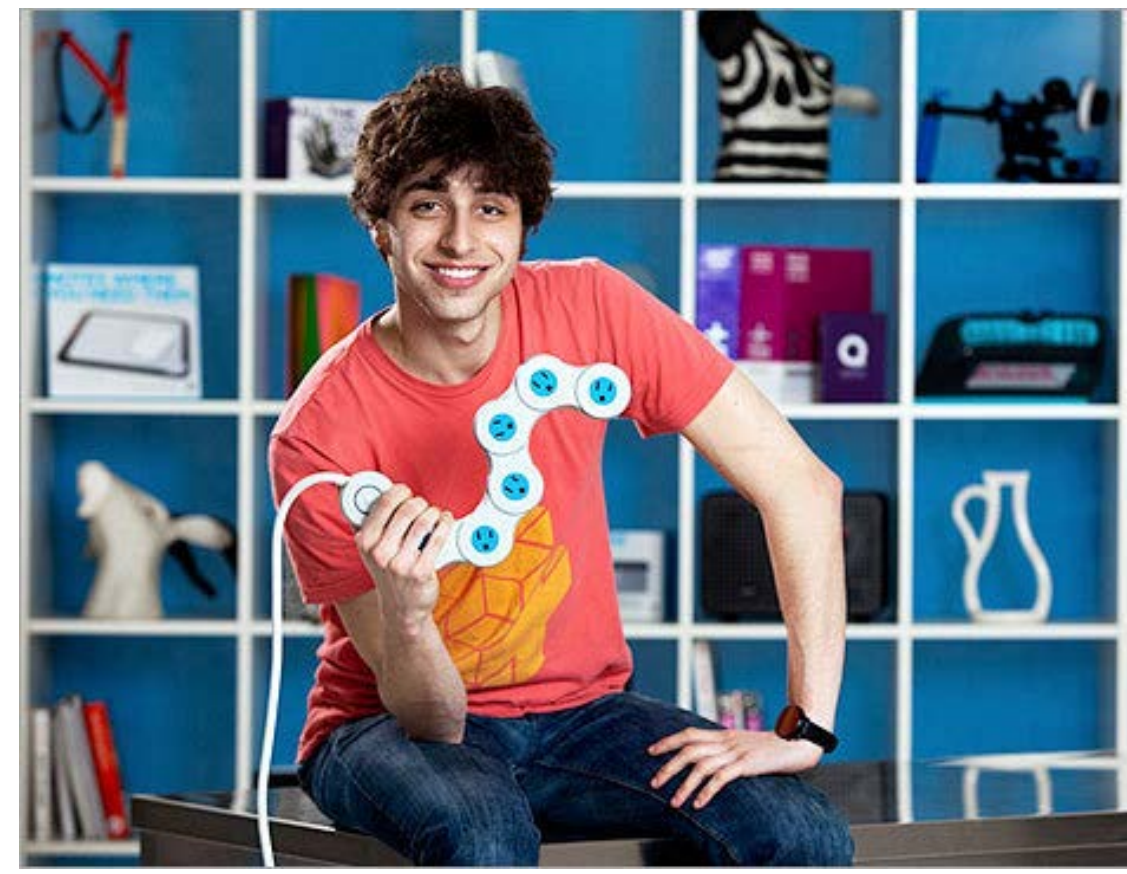

Figure 18. Quirky's product example-Pivot Power, from $\underline{\text { http://archive.boston.com/lifestyle/articles/2011/08/18/jake_zien_has_designs_on_a_solu }}$ tion/.

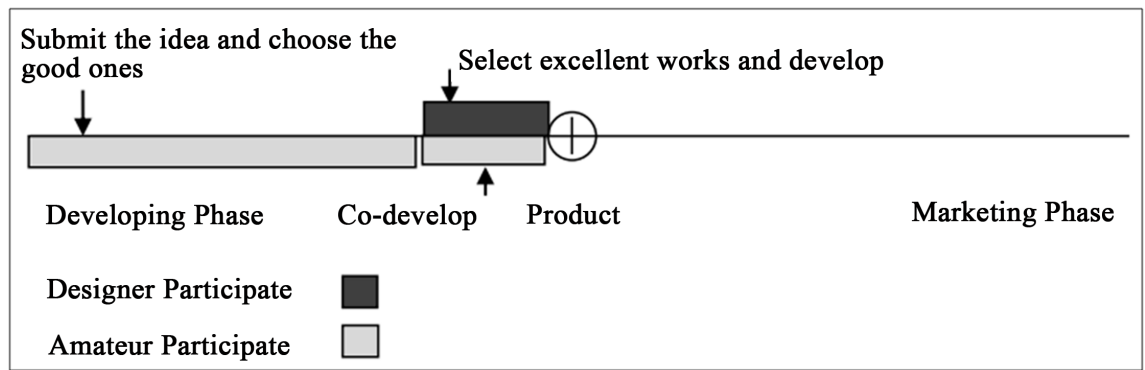

Figure 19. The collaborate phase map of Quirky.

kept in mind rather than shown on the internet. For this reason, designers have the responsibility to help the amateurs to understand various ways to bring the idea into the market.

\subsection{Kickstarter}

Kickstarter is a crowd funding platform in Figure 20. It launched in 2009 in the United States. The company's stated mission is to help bring creative projects to life. Kickstarter claims it has received over $\$ 1$ billion in pledges from 5.7 million donors to fund 135,000 projects, such as films, music, stage shows, comics, journalism, video games, and food-related projects.

The amateurs have two roles in this case in Figure 21. They both can be the entrepreneurs and the supporters. As entrepreneurs, they can upload their creative startup projects with a short video and description. And as the supporters, they choose any of the project they like and support an amount of money by 


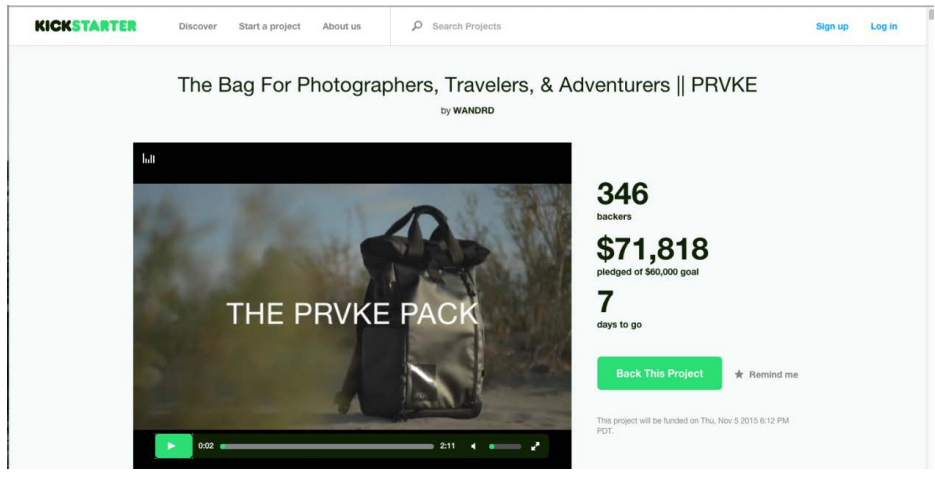

Figure 20. The web interface of Kickstarter, from http://www.kickstarter.com.

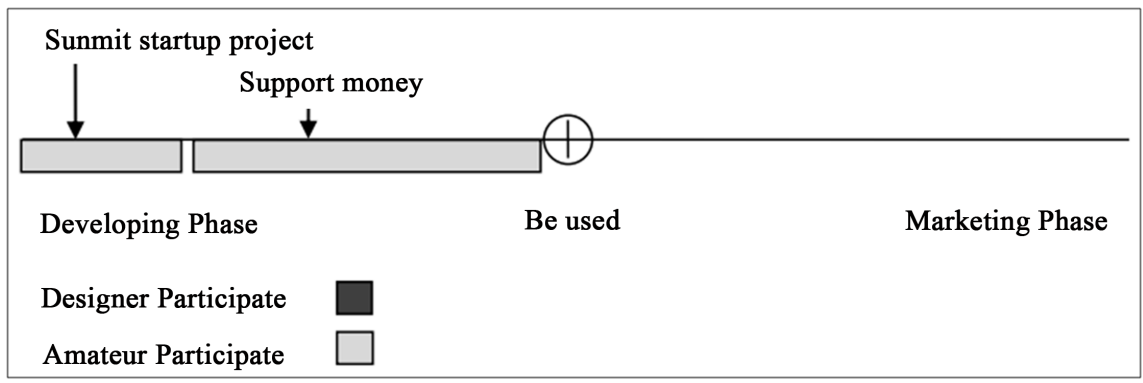

Figure 21. The collaborate phase map of Kickstarter.

Amazon transfer. Finally, Kickstarter gets 5\% of the funds, Amazon gets 3\% to $5 \%$, and all the others will be used to support the startup idea.

As the most famous co-funding website in the world, Kickstarter got big success and a number of imitators around the world. It initiates a new form of creating the long-tail value. Special-interest products and projects get the chance to see the market, and get financial support as well as accurate marketing research. Kickstarter uses the mode of "all-or-nothing" to ensure the quality of the projects, which means only the project that reaches the funding target amount can get it. From the burgeoning number of projects, Kickstarter learned that they needed to control the speed of expansion. Instead of owning a large number of mediocre design, it is better to develop a few but influential products. These kinds of sophisticated complete products not only attract more people to join the service, but also set up the standard for other projects.

\subsection{0. [Im]possible Living}

[Im]possible living started from 2013 in Italy. It is a crowed-sourced web platform, in Figure 22, dedicated to the re-use of abandoned buildings all over the world. It provides tools and services for people who try to raise, discuss and trigger a regeneration process of unused buildings supported by a wide community. The mission is to give a new life to all the abandoned buildings around the world through an innovative way: creating a global community involved in the reactivation of abandoned building, a crowd-sourced process enabling new solutions to solve the abandonment issue. 


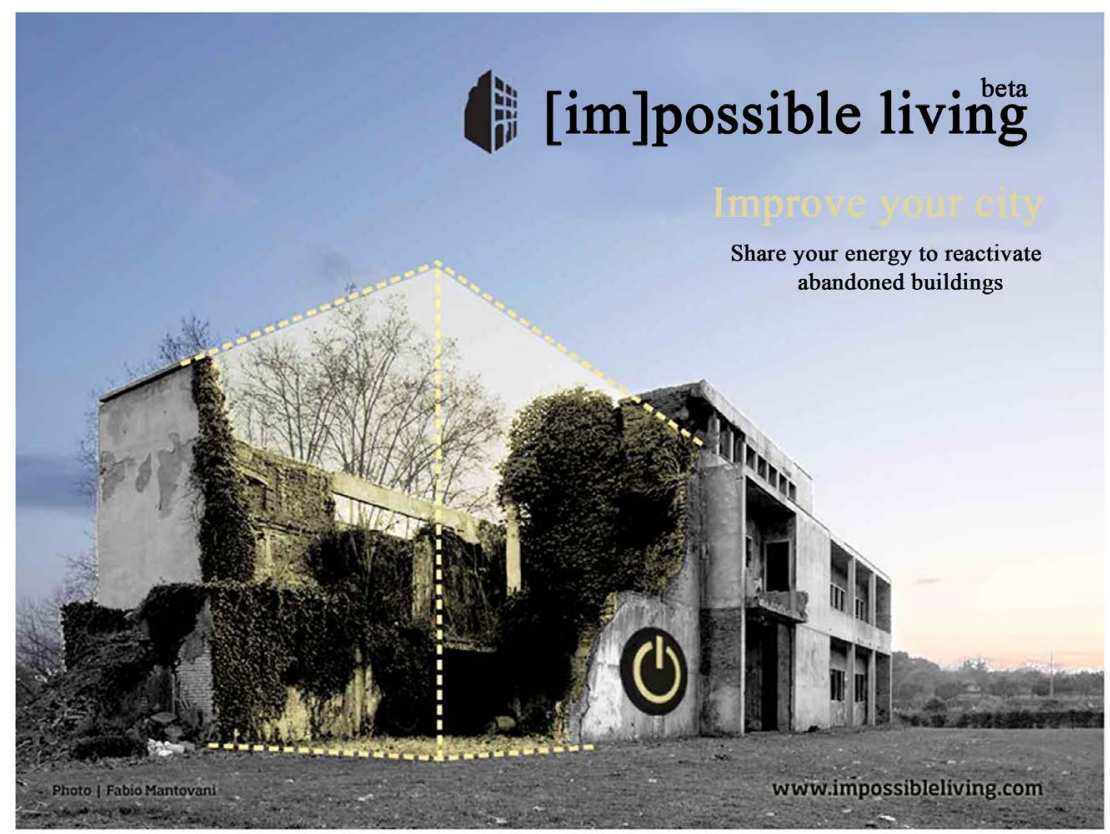

Figure 22. The advertising picture of (im)possible living, from https://ecosistemaurbano.org/english/metamap-impossible-living/.

Every citizen can participate to map the abandoned building around them. They discuss together online to try to get fascinating ideas about re-using these buildings. They can contribute to a project by uploading photographs or videos about the building on the project page to offer information and resources. If someone gets a good ideas, he/she can describe them with words, drawing or any other way. At the end, the staff from [im]possible living will select the good ones, and coordinate with the idea provider and other relevant personnel, to realize the ideas to create social and economic value as shown in Figure 23.

[im]possible Living as the other cases, like HousingLab and Darsena Pioniera also from Italy, lead the new trend of democracy of social innovation from the bottoms up. They are all based on creative communities and collaborative organizations and promoted by active local amateurs. Amateurs are given the duty of government and professional department and have proven its possibility and superiority. As a new field of innovation, these approaches also have their own limits. As [im]possible Living, it has a good mission, but not enough structure to achieve the final goal of massively making abandoned building revived.

\section{Discussion and Implications}

In Table 2, the comparison of these ten cases is presented with five aspects including type, collaborate mode, amateurs' role, designers' role and their business logic. These ten cases consist of the projects in different development phases, from the research project as Every Use, to the new strategy of a successful brand as $100 \%$ TobeUse, to new startup platforms as [im]possible Living, and even the impeccable platforms as Kickstarter. Since they stay in different developing phases, they face different problems and have their own advancement. 


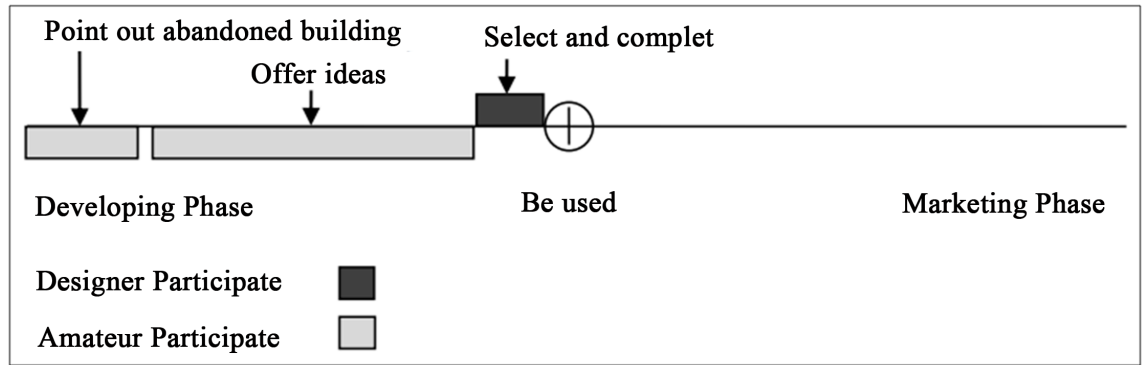

Figure 23. The collaborate phase map of [im]possible Living.

Table 2. Comparison of ten cases of amateur participation in design.

\begin{tabular}{|c|c|c|c|c|c|}
\hline Case & Type & $\begin{array}{l}\text { Collaborate } \\
\text { Mode }\end{array}$ & $\begin{array}{c}\text { Amateurs' } \\
\text { Role }\end{array}$ & $\begin{array}{c}\text { Designers' } \\
\text { Role }\end{array}$ & $\begin{array}{l}\text { Business } \\
\text { Logic }\end{array}$ \\
\hline Every Use & Project & Share & Appropriating & Get Inspired & - \\
\hline Pinterest & Platform & Share & Idea & Get Inspired & Advertising \\
\hline $100 \%$ Tobeus & Single Brand & Experience & Idea & Design & Products sell \\
\hline Julep & Single Brand & Co-create & Suggest & Design & Products sell \\
\hline Casetagram & Single Brand & $\begin{array}{l}\text { Customize/ } \\
\text { Social network }\end{array}$ & DIY & - & Products sell \\
\hline $\begin{array}{c}\text { Logo } \\
\text { Tournament }\end{array}$ & Platform & Competition & Design & - & Share Profit \\
\hline Threadless & Single Brand & Crowdsourcing & Design & Select/Improve & Products sell \\
\hline Quirky & Platform & Crowdsourcing & Innovation & Select/Improve & Products sell \\
\hline Kickstarter & Platform & Co-funding & $\begin{array}{l}\text { Entrepreneurial } \\
\text { Innovation }\end{array}$ & - & Share Profit \\
\hline $\begin{array}{c}\text { [im]possible } \\
\text { Living }\end{array}$ & Platform & Co-create & $\begin{array}{c}\text { Social } \\
\text { Innovation }\end{array}$ & Select/Improve & Share Profit \\
\hline
\end{tabular}

Amateurs act with various roles with different levels of participation. From simply appropriating the existing products, to adding tiny creativity to improve and personalize, from creating ideas or concepts about their lifestyle, to giving suggestions to professional designers, and even using their innovation to contribute to society or commercial value. The amateur's different capabilities are guided to work for the different stages of design. In fact, the degree of designers' participation and amateurs' participation are not inversely proportional. As in $100 \%$ TobeUse and Julep, designers take the majority of the design work under amateurs' assistant. In contrary, for some other cases as Treadless, Quirky and [im]possible Living, the amateurs take the most of the innovative works, and professional designers just help to choose the good ideas and push them further. And in some other cases, amateurs can even well organize the innovation process by themselves, and designers only take very limited responsibility and get inspired from amateurs' work.

These cases proved that amateurs have the ability to actively collaborate with each other under the vested rules. They cooperate with other amateurs with the 
same interest, share information each other and try their best to achieve the given design goal. Among these ways, two iconic models lead out: crowd-sourcing, which offer the single task to mass common people, and co-funding, which gather money from mass people to support the single target. And these two models also proved the central value of collaborative innovation: gathering wisdom and money to make ambitious dreams come true.

The ten cases are based on three kinds of business logic. Product-selling is the most basic one. In these cases, the companies get money from selling out the creative products co-created by amateurs and designers. This co-creation process attracts more and more people by its value. And the second mode is sharing profit with amateurs. Rights and profits are given to the users, who then obtain tiny bonus shares from each successful case.

\section{Suggestions for Assisting Amateurs and Designers}

From the theoretical study and case study, it could be confirmed that amateurism should be promoted, rather than overlooked. Amateurs have freedom to develop the skills that can make a make a difference. At the same time, the amateurs also avoid the professional designer's fixed opinion, which can motivate them to put all their passion into the innovation.

The designer's capability is still important; an excellent designer is able to organize and stimulate the co-creation activities with the people from multi-disciplines. Design, instead of a skill, is more of the problem solving process and future imagining, in which all people in society have their capability to participate. In this process, what the design experts should do is not control, but trigger and support these innovations. To communicate with people to understand their desire, interpret and prototype them gives a new experience with real impact to society.

This means involving amateurs is the most important task to be discussed. The case study offered four approaches to stimulate the amateurs who never thought of participating in design activity. First is rendering the atmosphere of "mistake welcoming". Every Use set the example to tell the amateurs: making mistakes is interesting and designers can even create new designs based on them. Secondly, amateurs are more easily accept and join the activities they are interested in. By offering amateurs freedom to make their own interest groups rather than push them too much to make innovation, an effective road is laid. Luckily, when companies start to make this change, they are not alone. A number of existing resources from other fields are available as the basis to build the "network of social networks" to improve upon.

\section{Conclusion and Future Research}

"99\% of the smartest people work elsewhere." Even under the globalized background and internet support, they are still dispersed. This research presented an overview on the academic research result in the amateurs' collaborative innova- 
tion field, and at the same time, the case study researched the practical innovation modes taking place in various fields. The results proved that amateurs' participation already contributed to companies' idea generation, and got commercial success in some industries. Some suggestions were given for assisting amateurs and designers to adapt to the new design process changes, and rules are offered for the companies to localize their collaborate mode with a long-term strategy. More firsthand researches and face-to-face communication with the leading companies, designers and amateurs should be put into practice for the future studies.

This research is mainly based on case studies. In order to derive quantitative insights to assess amateurs' contribution to the innovation process, future research could conduct a range of surveys among designers and amateur participants. In addition, an in-depth case study around amateur-designer collaborated innovation could reveal important success factors and barriers for innovation managers to know.

\section{Conflicts of Interest}

The authors declare no conflicts of interest regarding the publication of this paper.

\section{References}

Carlson, N. (2012). Inside Pinterest: An Overnight Success Four Years in the Making. New York: Business Insider.

Casati, A. (2012). Designing for Democracy: Definition of a Fruitful Participatory System in Monza. Milano: Politecnico di Milano Scuola del Design.

Chesbrough, H. W. (2003). Open Innovation: The New Imperative for Creating and Profiting from Technology. Boston, MA: Harvard Business School Press.

Hitotsuishi, A. L.-V. (2012). Co-Creation and Open Innovation: Common Traits and Differences. Milano: Politecnico di Milano, Master of Science in Management, Economics and Industrial Engineering.

Lee, W. (2013). Design Project Lecture, Korea Advanced Institute of Science and Technology (KAIST).

Levine, S. S., \& Prietula, M. J. (2013). Open Collaboration for Innovation: Principles and Performance. Organization Science, 25, 1414-1433.

https://doi.org/10.1287/orsc.2013.0872

Manizni, E. (2013a). People-as-Asset: Grassroots Innovation and Design in the (Economic, Social, Environmental) Crisis. Milano: Politecnico di Milano DISDESIS Network.

Manizni, E. (2013b). Social Innovation and Design: Enabling, Replicating and Synergizing. Milano: Politecnico di Milano DISDESIS Network.

Osterwalder, A., \& Pigneur, Y. (2010). Business Model Generation. Hoboken, NJ: John Wiley \& Sons, Inc.

Telalbasic, I. (2012). What Has the Designer's Role Become in a System Where Products Have Turned into Processes and Ownership into Access? Milano: Politecnico di Milano Faculty of Design. 
TIBCO (2014). http://www.tibco.com/blog/2014/02/27/the-true-solution-to-big-data

Von Hippel, E. (2005). Democratizing Innovation. Cambridge, MA: The MIT Press. https://doi.org/10.7551/mitpress/2333.001.0001 